\title{
HPV 18 L1-VLP
}

National Cancer Institute

\section{Source}

National Cancer Institute. HPV 18 L1-VLP. NCI Thesaurus. Code C49275.

Noninfectious, synthetic, virus-like particles (VLP) containing the major viral capsid protein, $\mathrm{L} 1$, of the human papillomavirus type 18 with potential immunoprotective activity. Vaccination with HPV 18 L1-VLP may stimulate the host immune system to mount cytotoxic T lymphocyte $(C T L)$ response against cells positive for HPV 18, thereby preventing cervical infection upon exposure to HPV type 18. 